\title{
Influence of solvents on the bond strength of resin sealer to intraradicular dentin after retreatment
}

\author{
Marcelo PALHAIS(a) \\ Manoel Damião SOUSA-NETO(b) \\ Fuad Jacob Abi RACHED-JUNIOR ${ }^{(a)}$ \\ Mariana Carvalho de Andrade \\ AMARAL(a) \\ Edson ALFREDO(a) \\ Carlos Eduardo Saraiva MIRANDA(a) \\ Yara Teresinha Corrêa \\ SILVA-SOUSA(a)
}

(a) Universidade de Ribeirão Preto, School of Dentistry, Ribeirão Preto, SP, Brazil.

(b) Universidade de São Paulo - USP, School of Dentistry of Ribeirão Preto, Ribeirão Preto, SP, Brazil.

Declaration of Interests: The authors certify that they have no commercial or associative interest that represents a conflict of interest in connection with the manuscript.

\section{Corresponding Author:}

Fuad Jacob Abi Rached-Junior

E-mail: rached-junior@hotmail.com

http://doi.org/10.1590/1807-3107BOR-2017.vol31.0011

Submitted: Aug 15, 2016

Accepted for publication: Nov 21, 2016

Last revision: Dec 05, 2016

\begin{abstract}
This study evaluated the removal of filling material with ProTaper Universal Rotary Retreatment system (PTR) combined with solvents and the influence of solvents on the bond strength (PBS) of sealer to intraradicular dentin after canal reobturation. Roots were endodontically treated and distributed to five groups $(n=12)$. The control group was not retreated. In the four experimental groups, canals were retreated with PTR alone or in combination with xylol, orange oil, and eucalyptol. After filling material removal, two specimens of each group were analysed by SEM and $\mu \mathrm{CT}$ to verify the presence of filling remnants on root canal walls. The other roots were reobturated and sectioned in 1-mm-thick dentin slices that were subjected to the push-out test. Data were analysed by two-way ANOVA and Tukey's test $(\alpha=0.05)$. SEM and $\mu \mathrm{CT}$ analysis revealed that all retreatment techniques left filling remnants on canal walls. The control group $(3.47 \pm 1.21)$ presented significantly higher $(p<0.05)$ PBS than the experimental groups. The groups retreated with PTR alone $(2.59 \pm 0.99)$ or combined with xylol $(2.54 \pm 0.77)$ and orange oil $(2.32 \pm 0.93)$ presented similar bond strength $(\mathrm{p}>0.05)$, and differed significantly from the group with eucalyptol $(1.89 \pm 0.63)$. The solvents reduced the PBS of the sealer to dentin and no retreatment technique promoted complete removal of filling material.
\end{abstract}

Keywords: Endodontics; Retreatment; Solvents.

\section{Introduction}

Removal of the filling material is one of the critical points of endodontic retreatment because filling remnants adhered to the dentinal walls may harbor microorganisms and necrotic tissue residue that lead to persistence of periradicular infection. ${ }^{1}$ There are various methods for removing the filling material, including the use of stainless steel or nickel-titanium hand or rotary instruments alone or combined with heated pluggers, chemical solvents, or more recently, ultrasonics. ${ }^{2,3,4}$ However, reports have claimed that none of these retreatment techniques provide complete removal of previous filling material from the root canals, and there is no consensus with respect to their efficacy. ${ }^{5,6,7}$

The adhesion between dental structures and resin-based sealers is the result of a physicochemical interaction across the interface, 
which allows the union between the filling material and root canal walls. This process is important in static and dynamic situations. In static circumstances, the adhesion eliminates spaces that allow the infiltration of fluids into the sealer/dentin interface. ${ }^{8,9}$ In dynamic situations, the adhesion is necessary to avoid sealer dislodgment during operative procedures. ${ }^{9,10}$

In laboratory studies, removal of the filling material has traditionally been assessed radiographically ${ }^{4}$ by rendering the teeth transparent with clearing techniques ${ }^{11}$ or by examination under endodontic operating microscopes followed by morphometric analysis of digital images, ${ }^{4}$ scanning electron microscopy (SEM), ${ }^{12}$ and confocal scanning laser microscopy (CSLM). ${ }^{13}$ More recently, nondestructive protocols using $\mu \mathrm{CT}$ have been shown to provide an accurate quantitative and qualitative evaluation of the residual filling material and the amount of root canal enlargement after retreatment procedures. ${ }^{14,15}$

This study evaluated the influence of the solvents on the push-out bond strength (PBS) of a resin sealer in the intraradicular dentin after endodontic retreatment.

\section{Methodology}

This study was approved by the Ethics in Human Research Committee (\#55/2011).

\section{Endodontic treatment}

Sixty human maxillary canines with completely formed apices and a single canal without calcifications had the crowns removed at the cementoenamel junction to obtain a standardized root length of $19 \mathrm{~mm}$ for each tooth.

Canal patency was checked by passively introducing a size $15 \mathrm{~K}$-file into each canal until its tip was visible at the apical foramen with a $\times 4$ magnifier. The working length $(\mathrm{WL})$ was established by withdrawing $1 \mathrm{~mm}$ from this length.

The coronal third was preflared with LA Axxes D1 \#20 (SybronEndo, Orange, CA, USA), and the canals were instrumented with ProTaper Universal Rotary system (Dentsply Maillefer, Ballaigues, Switzerland). The files were attached to a 64:1 gear reduction handpiece (Anthogyr, Sallanches,
France), with continuous movement at $2 \mathrm{~N} / \mathrm{cm}$ torque, powered by an electric engine (Endo Plus VK Driller, São Paulo, SP, Brazil), and were used in the following sequence: SX, S1, S2, F1, F2, F3, F4 and F5. The canals were irrigated with $2 \mathrm{~mL}$ of $1.0 \% \mathrm{NaOCl}$ at each change of file during chemomechanical preparation, filled with $5 \mathrm{~mL}$ of $17 \%$ EDTA for $5 \mathrm{~min}$, flushed with $20 \mathrm{~mL}$ of distilled water, and dried with absorbent paper points. The root canals were filled with AH Plus sealer, gutta-percha points (F5 and accessories) were inserted using the lateral condensation technique, and the roots were stored at $37^{\circ} \mathrm{C}$ and $95 \%$ humidity for 7 days.

\section{Endodontic retreatment}

The roots were randomly distributed into five groups $(n=12)$. Group 1 was a positive control group and not subjected to retreatment. In the remaining four experimental groups, the canals were emptied using PTR alone (group 2), with the addition of the solvent xylol (Bioquimica Industria Farmaceutica, São José do Rio Preto, SP, Brazil) (group 3), orange oil (Citrol; Biodinâmica Química and Farmacêutica, Ibiporã, PR, Brazil) (group 4), and eucalyptol (ASFER Industria Química, São Caetano do Sul, SP, Brazil) (group 5).

In the groups submitted to retreatment, the filling material was removed using a heated plugger in the coronal and middle thirds and a ProTaper Universal Retreatment D3 file in the apical third. The D3 file was used with a brushing action against the canal walls until reaching WL. When $1 \mathrm{~mm}$ of filling material was left apically, the final canal portion was worked using sizes 15 and $20 \mathrm{~K}$-files with $1 \% \mathrm{NaOCl}$ irrigation. When the solvent was used, one drop was delivered at the canal entrance only before activation of the D3 file. In all retreated groups, canal refinement was performed using the shaping (S1 and SX in the coronal third and $\mathrm{S} 2$ in the middle third) and finishing instruments (F1 to F5) at $2 \mathrm{~N} / \mathrm{cm}$ torque and $250 \mathrm{rpm}$. During refinement, the root canal was irrigated with $5 \mathrm{~mL}$ of $1 \% \mathrm{NaOCl}$ solution between each instrument change, followed by $5 \mathrm{~mL} \mathrm{17 \%} \mathrm{EDTA} \mathrm{for} 5 \mathrm{~min}$, flushed with $20 \mathrm{~mL}$ of distilled water, and dried using absorbent paper points. 


\section{Qualitative analysis: $\mu C T$ and SEM}

$\mu \mathrm{CT}$

Two roots of each group selected at random were subjected to $\mu \mathrm{CT}$ qualitative analysis using a $\mu$-CT scanner (SkyScan 1174v2; SkyScan N.V., Kontich, Belgium) set at exposure parameters of $50 \mathrm{kV}, 800 \mathrm{~mA}$, $40 \mathrm{~W}$ maximum power, $30 \mu \mathrm{m}$ spatial resolution, and projections from a $360^{\circ}$ acquisition rotation. A set of 3D images was obtained for each sample after reconstruction using the SkyScan's cluster reconstruction software (NRecon).

\section{SEM}

The same roots used in the $\mu \mathrm{CT}$ scanning were examined by SEM. The roots were split longitudinally and the halves were grooved to define coronal, middle, and apical thirds and subjected to routine processing and examined using a scanning electron microscope (LEO 440; Carl Zeiss SMT Ltd., Cambridge, UK). SEM micrographs ( $\times 3500$ magnifications) were taken to visualize filling remnants on canal walls of the coronal, middle, and apical thirds.

\section{Push-out test}

For the push out test, the root canals $(n=10)$ were refilled with $\mathrm{AH}$ Plus sealer, gutta-percha points (F5 and accessories) were inserted using the lateral condensation technique, and stored at $37^{\circ} \mathrm{C}$ and $95 \%$ humidity for 7 days.

The roots were sectioned into slices with $1.0 \mathrm{~mm}$ thickness using a precision cutting machine (Isomet 1000; Buehler, Lake Forest, IL, USA). The first slice of the coronal, middle, and apical thirds was selected for the push-out test in a universal testing machine (Instron Corporation, Canton, MA, USA) at a crosshead speed of $0.5 \mathrm{~mm} \mathrm{~min}^{-1}$. A stainless steel support was used to hold the specimens in such a way that the side with the smaller diameter of the root canal faced upward and was aligned to the shaft that would exert the pressure load on the sealer (apical-coronally). Four millimeter-long points were used with tip diameters of 1.0, 0.6 , and $0.4 \mathrm{~mm}$ for the coronal, middle, and apical third, respectively.

The force needed to dislodge the filling material ( $\mathrm{F}$; in $\mathrm{kN}$ ) was transformed into tension ( $\mathrm{r}$; in $\mathrm{MPa}$ ) by dividing the force with the adhesive area of the filling material (SL; in $\mathrm{mm}^{2}$ ), using the following equation: $\mathrm{r}=\mathrm{F} / \mathrm{SL}$. SL was calculated using the following equation: $S L=p(R+r) g$, where $S L=$ sealer bonding area; $\mathrm{p}=3.14 ; \mathrm{R}=$ mean radius of the coronal canal, in $\mathrm{mm} ; \mathrm{r}=$ mean radius of the apical canal, in $\mathrm{mm}$; and $g=$ height relative to the tapered inverted cone, in $\mathrm{mm}$. Mean PBS values were statistically analyzed by two-way ANOVA and post-hoc Tukey's test $(\alpha=0.05)$.

After the push-out test, the specimens were examined using a magnifying glass at $\times 40$ to assess the failure modes (adhesive, cohesive, and mixed) resulting from sealer displacement from the specimen.

\section{Results}

\section{$\mu \mathrm{CT}$ analysis}

The $\mu \mathrm{CT}$ qualitative analysis revealed that filling remnants were predominantly found in the middle and coronal thirds in the specimens retreated with PTR alone. The use of solvents improved the cleaning efficacy, but filling remnants were found in three thirds of the specimens treated with xylol and orange oil. When eucalyptol was used, filling remnants remained only in the coronal third. The positive control group showed the complete filling of the root canal (Figure 1).

\section{SEM analysis}

Intraradicular dentin covered with filling remnants was found in the specimens retreated with PTR without solvent (Figure 2). When PTR was used with solvents, areas covered with the sealer were still present on dentin surface, but areas free of filling remnants with open dentinal tubules could also be seen (Figure 2).

\section{Push-out test}

Table 1 presents the mean PBS (in MPa) for sealer displacement after reobturation. Statistically significant difference $(p<0.05)$ was found among retreatment techniques and root thirds, while no significant effect was observed in their interaction $(p>0.05)$. The positive control group presented significantly higher $(p<0.05)$ PBS of the sealer in the intraradicular dentin than the experimental groups. The groups retreated with PTR alone or in 


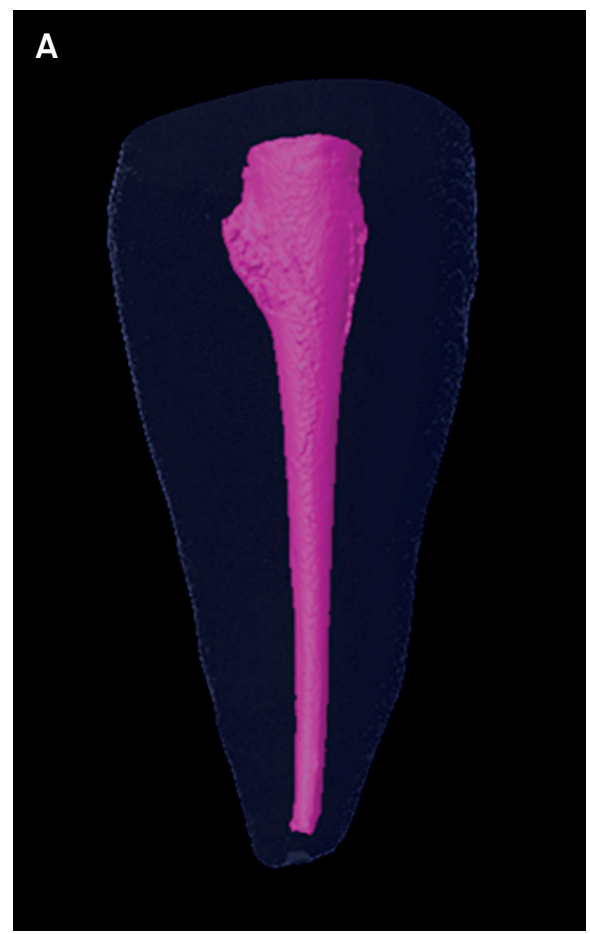

\section{$\mathbf{B}$}
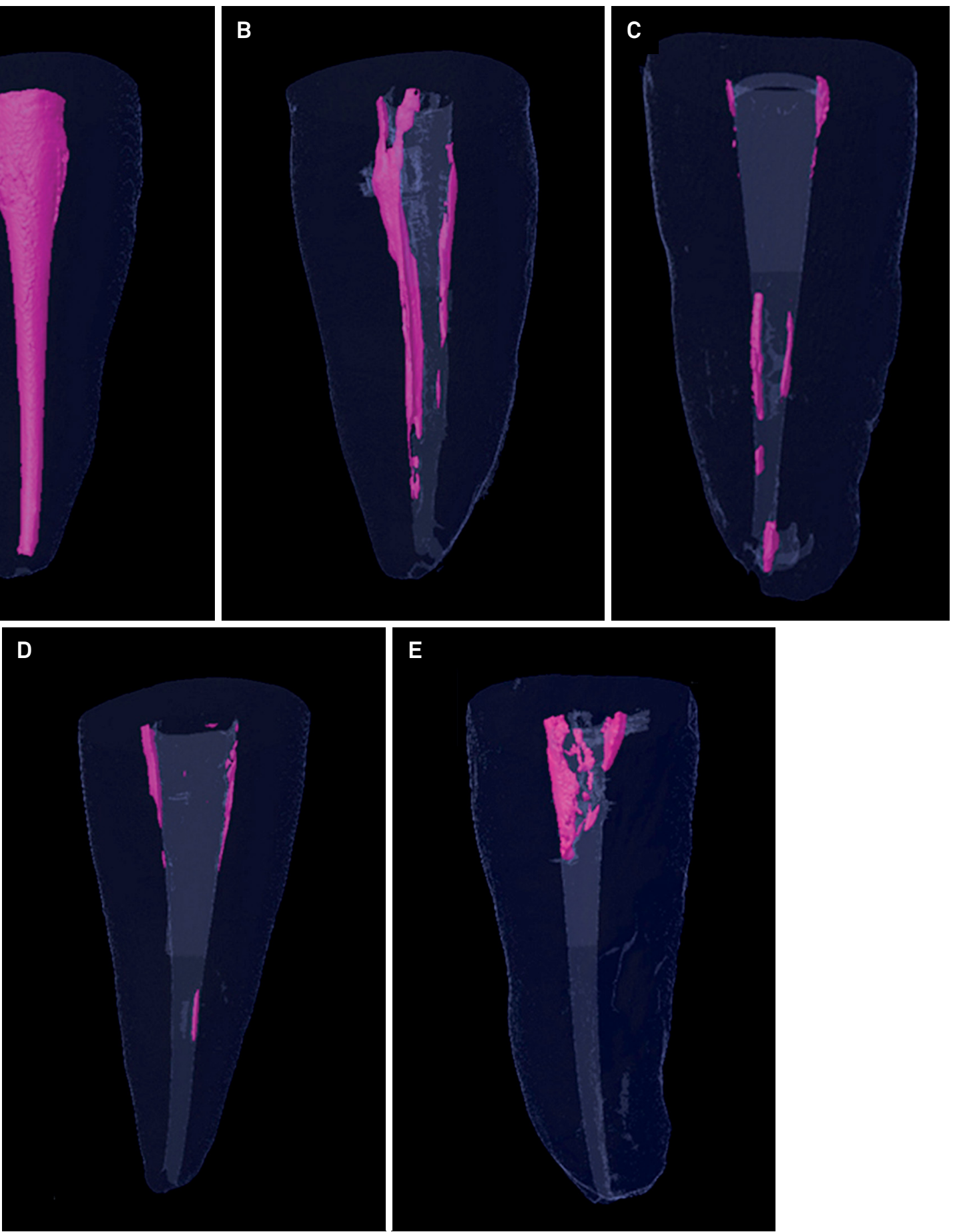

E

Figure 1. $\mu$ CT scans of the positive control group and experimental groups. A (positive control): Filled root canal. B (PTR): presence of filling material remnants in the middle and coronal thirds. C (PTR/xylol): presence of filling material remnants in the three canal thirds. D (PTR/orange oil): presence of filling material remnants in the middle and coronal thirds. E (PTR/eucalyptol): presence of filling material remnants only in the coronal third.

combination with xylol and orange oil presented intermediate $(\mathrm{p}>0.05)$ PBS. Retreatment with PTR and eucalyptol resulted in the lowest PBS, being similar to retreated with PTR and orange oil $(\mathrm{p}>0.05)$ and different $(p<0.05)$ from the other groups. The apical third presented the lowest PBS values $(p<0.05)$. 

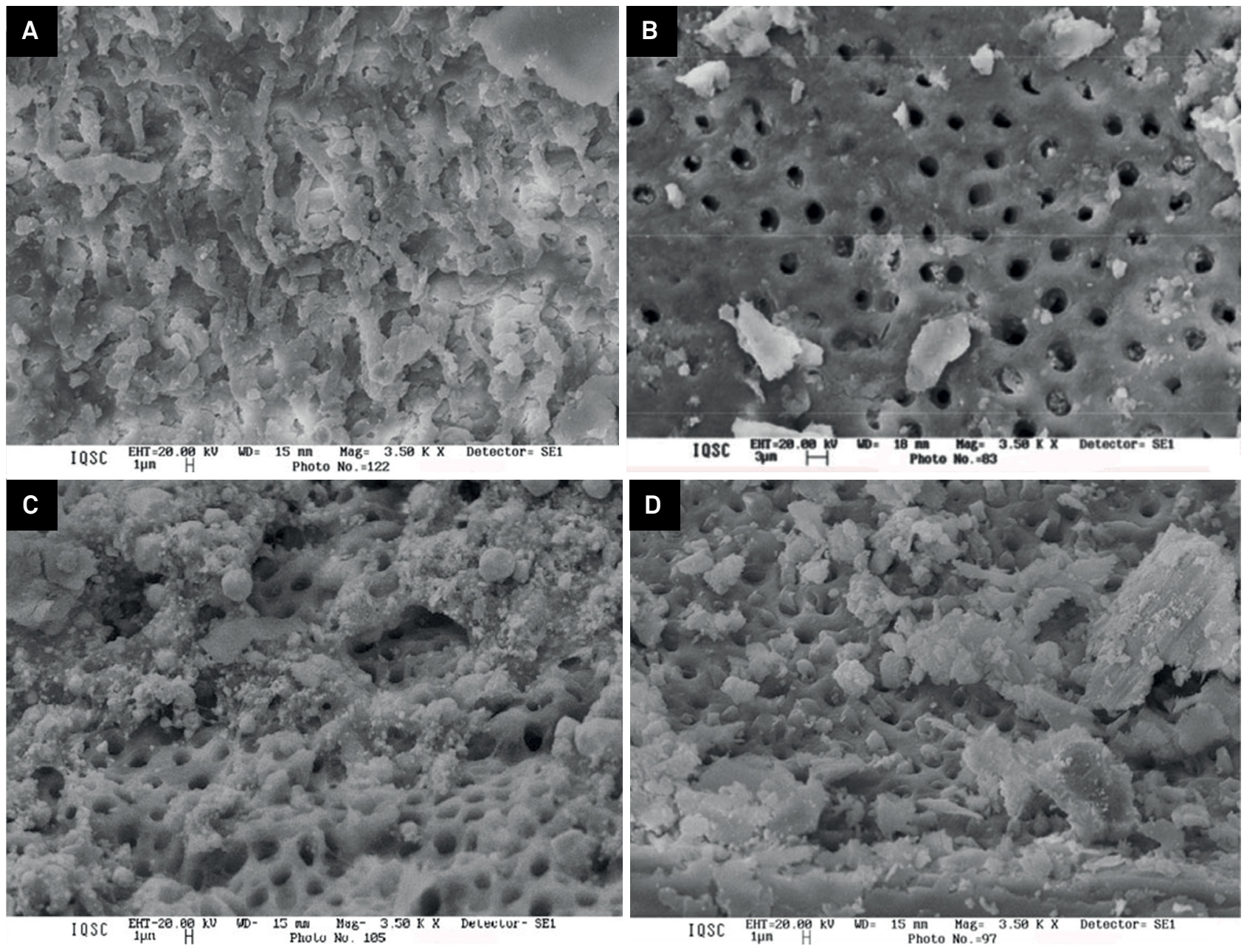

Figure 2. SEM micrographs of the root canal thirds after filling material removal in the different experimental groups. ProTaper alone (A): the root canal wall is covered by residual filling material in the three root canal thirds. PTR/ xylol (B): canal walls with exposed dentinal tubules. PTR/ orange oil (C): filling material remnants and exposure of dentinal tubules. PTR/eucalyptol (D): root canal walls with filling material remnants and exposure of dentinal tubules.

No statistically significant difference was observed between the coronal and middle thirds ( $p>0.05)$.

Failure mode distribution is displayed in Table 2. For all retreatment techniques, there was a predominance of cohesive failures in the three root canal thirds (Table 2).

\section{Discussion}

Here the influence of chemical solvents on bond strength of the sealer in the intraradicular dentin employing AH Plus, after canal reobturation, was evaluated using the push-out test. This study was proposed since there is little information in literature about the best solvents for resin materials as root canal sealer AH Plus. The push-out test was selected due to its suitability to evaluate the effect of solvents on bond strength.

For the push-out test, the alignment of the specimens to the shaft was carefully established in an accurate and reproducible way. Thus, the shaft was maintained in a centralized manner to avoid its contact with the dentin during testing, when the material was pushed and dislodged from the canal wall. In addition, filling remnants left in retreated root canals were evaluated by qualitative analysis of $\mu \mathrm{CT}$.

The use of solvents is essential for facilitating the removal of filling material from areas of the root canal 
that are inaccessible to the endodontic instruments. ${ }^{10,13,16}$ However, while gutta-percha can be removed without great difficulty with the use of organic solvents combined with endodontic instruments, the endodontic sealer can resist dissolution and complete removal might not be achieved. ${ }^{17,18}$ These results were confirmed by SEM; the intraradicular dentin was observed to be covered by filling remnants when PTR was used without a solvent, whereas sealer-free areas with open tubules could be observed on intraradicular dentin surfaces when solvents were applied. However, as SEM is an ultrastructural analysis, it was not possible to verify the differences among the solvents, which reinforced the contribution of $\mu \mathrm{CT}$ for this kind of study.

$\mu \mathrm{CT}$ in its nondesctructive methodology allows precise three-dimensional quail-quantitative evaluation of the residual filling material. ${ }^{15,19}$ Here this technique allowed identification of areas covered with filling

Table 1. Means and standard deviations of bond strength (in MPa) for displacement of the sealer from the specimens after reobturation according to the retreatment techniques and root canal thirds.

\begin{tabular}{lc}
\hline Variable & Mean \pm S.D. \\
\hline Retreatment technique & \\
Positive control group & $3.47 \pm 1.21 \mathrm{a}$ \\
ProTaper & $2.59 \pm 0.99 \mathrm{~b}$ \\
ProTaper + xylol & $2.54 \pm 0.77 \mathrm{~b}$ \\
ProTaper + orange oil & $2.32 \pm 0.93 \mathrm{~b}, \mathrm{c}$ \\
ProTaper + eucalyptol & $1.89 \pm 0.63 \mathrm{c}$ \\
Root Thirds & \\
Coronal & $2.98 \pm 0.95 \mathrm{~A}$ \\
Middle & $2.86 \pm 1.11 \mathrm{~A}$ \\
Apical & $1.86 \pm 0.69 \mathrm{~B}$ \\
\hline
\end{tabular}

Different letters indicate statistically significant difference among treatments (lowercase letters) and among root thirds (uppercase letters); Tukey's test; $p<0.05$. remnants in the different radicular thirds. Although none of the retreatment techniques could completely remove the filling material from the root canals, the $\mu \mathrm{CT}$ qualitative analysis revealed that the use of PTR without solvent left filling remnants in all three root thirds.

Two fundamental criteria should determine how the solvents are chosen: their effectiveness and toxicity level. ${ }^{20}$ Thus, it's important to consider the possibility of replacing solvents with high levels of systemic and tissue-related toxicities. Therefore, orange oil would be a suitable alternative solvent to promote gutta-percha dissolution compared with potentially toxic solvents such as xylol. ${ }^{21}$ Further, the use of orange oil in endodontics is increasing because of its safety, biocompatibility, and non-carcinogenicity. ${ }^{22}$

Although the solvents facilitated filling removal of the material, they also probably contributed to creating a residual filling layer on the canal walls ${ }^{11}$ which affected the penetration of the sealer into the dentinal tubules after retreatment, reducing its bond strength in the intraradicular dentin. The solvents might cause alterations on the dentin surface, ${ }^{3}$ which could affect the bond strength. In this study lower bond strength was observed for all solvents when they were used in the reobturation procedure, despite the better removal of filling material promoted by them.

The results obtained in this study indicated that evaluated solvents presented a negative effect on bond strengths to root canal dentin. This solvent effect was also observed by Erdemir et al. ${ }^{20}$ The decrease in bond strength could be attributed to the modification of the chemical composition of the root canal dentin, which could change the bond strength. According to Kaufman et al., ${ }^{23}$ the level of calcium and phosphorus in human dentin was altered after treatment with chloroform or halothane.

Table 2. Distribution of failure modes (\%) in each root canal third after the push out test, according to the retreatment technique.

\begin{tabular}{|c|c|c|c|c|c|c|c|c|c|c|c|c|c|c|c|}
\hline \multirow{2}{*}{ Failure mode } & \multicolumn{3}{|c|}{ Positive control group } & \multicolumn{3}{|c|}{ ProTaper } & \multicolumn{3}{|c|}{ ProTaper/Xylol } & \multicolumn{3}{|c|}{ ProTaper/ orange oil } & \multicolumn{3}{|c|}{ ProTaper/ eucalypto } \\
\hline & CT & MT & AT & CT & MT & AT & CT & MT & AT & CT & MT & AT & CT & MT & AT \\
\hline Adhesive & 0 & 0 & 10 & 10 & 10 & 30 & 10 & 20 & 20 & 20 & 20 & 30 & 10 & 30 & 30 \\
\hline Cohesive & 80 & 70 & 50 & 60 & 50 & 40 & 60 & 50 & 50 & 50 & 50 & 50 & 60 & 40 & 50 \\
\hline Mixed & 20 & 30 & 40 & 30 & 40 & 30 & 30 & 30 & 30 & 40 & 30 & 20 & 30 & 30 & 20 \\
\hline
\end{tabular}

$\mathrm{CT}=$ coronal third; $\mathrm{MT}=$ middle third; $\mathrm{AT}=$ apical third . 
In a study about the dissolving efficacy of organic solvents on different root canal sealers by Martos et al. ${ }^{18}$ xylol and orange oil presented similar solvent effects with a significant solubility of the tested sealers, including an epoxi-resin based as AH Plus. Eucalyptol, by its turn, presented the worst solvent effect for the epoxi sealer. These results were the opposite of our findings, considering the qualitative analysis conducted using $\mu \mathrm{CT}$, which demonstrates that eucalyptol promoted a large removal of material, although its bond strength was smaller.

Contrary to the present study results, Topçuoğlu et al. ${ }^{24}$ observed that the eucalyptol solvent did not influence the AH Plus bond strength in the root canal dentin. This divergence of results could be related to the methods used because the filling technique for the first treatment and the retreatment were different from the previous study. Topçuoğlu et al. ${ }^{24}$ used a single cone technique, whereas the present study used lateral compaction. According to Rached-Júnior et al. ${ }^{25}$ the use of a spreader and accessory gutta-percha cones in the lateral compaction technique created lateral and apical cement dislocation forces that filled the root canal irregularities and dentin tubules differently from a single cone technique. Therefore, it can be assumed that the higher mechanical cement interweaving was related to the increased material removal resistance. Nevertheless, all studied solvents decreases the bond strength probably because of the chemical modifications promoted by them on the dentin wall. ${ }^{20}$

\section{References}

1. Abramovitz I, Relles-Bonar S, Baransi B, Kfir A. The effectiveness of a self-adjusting file to remove residual gutta-percha after retreatment with rotary files. Int Endod J. 45(4):386-92. http://doi.org/10.1111/j.1365-2591.2011.01988.x

2. Ezzie E, Fleury A, Solomon E, Spears R, He J. Efficacy of retreatment techniques for a resin-based root canal obturation material. J Endod. 2006;32(4):341-4. http://doi.org/10.1016/j.joen.2005.09.010

3. Shokouhinejad N, Sabeti MA, Hasheminasab M, Shafiei F, Shamshiri AR. Push-out bond strength of Resilon/Epiphany self-etch to intraradicular dentin after retreatment: a preliminary study. J Endod. 2010;36(3):493-6. http://doi.org/10.1016/j.joen.2009.11.009
Regardless of the retreatment technique, the bond strength was lower in the apical third. It could be explained by the fact that the coronal and middle thirds have dentinal tubules in a larger number and with greater diameter, which could facilitate sealer penetration and increase their adhesiveness. ${ }^{26}$

The predominance of cohesive failures after the push-out test for all retreatment techniques suggests that filling remnants adhering to the intraradicular dentin apparently did not interact with the filling material after retreatment, even though the same resin sealer was used for filling and refilling procedures. This could probably be attributed to the chemical modifications caused by the solvent effect on the remaining sealer.

Despite the decrease in the bond strength caused by the solvents, an improvement in the removal of the sealer was clearly observed by employing the qualitative analysis of $\mu \mathrm{CT}$. Eucalyptol and orange oil were statistically similar in terms of bond strength and should be considered as the best choice as a sealer solvent because they did not present health risks. However, further research is still necessary to better elucidate the mechanisms of action and effects of physicochemical properties of solvents on the intraradicular dentin and filling materials.

\section{Conclusion}

Our results indicated that the solvents reduced PBS of the sealer in dentin, and no retreatment technique promoted complete removal of filling material.

4. Kfir A, Tsesis I, Yakirevich E, Matalon S, Abramovitz I. The efficacy of five techniques for removing root filling material: microscopic versus radiographic evaluation. Int Endod J. 2012;45(1):35-41. http://doi.org/10.1111/j.1365-2591.2011.01944.x

5. Giuliani V, Cocchetti R, Pagavino G. Efficacy of ProTaper universal retreatment files in removing filling materials during root canal retreatment. J Endod. 2008;34(11):1381-4. http://doi.org/10.1016/j.joen.2008.08.002

6. Takahashi CM, Cunha RS, Martin AS, Fontana CE, Silveira CF, Bueno CES. In vitro evaluation of the effectiveness of ProTaper universal rotary retreatment system for gutta-percha removal with or without a solvent. J Endod. 2009;35(11):1580-3. http://doi.org/10.1016/j.joen.2009.07.015 
7. Fenoul G, Meless GD, Pérez F. The efficacy of R-Endo rotary NiTi and stainless-steel hand instruments to remove gutta-percha and Resilon. Int Endod J. 2010;43(2):135-41. http://doi.org/10.1111/j.1365-2591.2009.01653.x

8. Ørstavik D. Physical properties of root canal sealers: measurement of flow, working time, and compressive strength. Int Endod J. 1983;16(3):99-107. http://doi.org/10.1111/j.1365-2591.1983.tb01307.x

9. Kaya BU, Keçeci AD, Orhan H, Belli S.

Micropush-out strengths of gutta-percha versus thermoplastic synthetic polymer-based systems: an ex vivo study. Int Endod J. 2008;41(3):211-218. http://doi.org/ 10.1111/j.1365-2591.2007.01342.x

10. Rached-Junior FJ, Sousa-Neto MD, Souza-Gabriel AE, Duarte MA, Silva-Sousa YT. Impact of remaining zinc oxide-eugenol-based sealer on the bond strength of a resinous sealer to dentine after root canal retreatment. Int Endod J. 2014;47(5):463-9. http://doi.org/10.1111/iej.12170

11. Gu LS, Ling JQ, Wei X Huang XY. Efficacy of ProTaper Universal rotary retreatment system for gutta-percha removal from root canals. Int Endod J. 2008;41(4):288-95. http://doi.org/10.1111/j.1365-2591.2007.01350.x

12. Cunha RS, De Martin AS, Barros PP, Silva FM, Jacinto RC, Bueno CES. In vitro evaluation of the cleansing working time and analysis of the amount of gutta-percha or Resilon remnants in the root canal walls after instrumentation for endodontic retreatment. J Endod. 2007;33(12):1426-8. http://doi.org/10.1016/j.joen.2007.07.004

13. Rached-Júnior FA, Sousa-Neto MD, Bruniera JF Duarte MA, Silva-Sousa YT. Confocal microscopy assessment of filling material remaining on root canal walls after retreatment. Int Endod J. 2014;47(3):264-70. http://doi.org/10.1111/iej.12142

14. Rödig T, Hausdörfer T, Konietschke F, Dullin C, Hahn W, Hülsmann M. Efficacy of D-RaCe and ProTaper Universal Retreatment NiTi instruments and hand files in removing gutta-percha from curved root canals: a micro-computed tomography study. Int Endod J. 2012;45(6):580-9. http://doi.org/10.1111/j.1365-2591.2012.02014.x

15. Rödig T, Kupis J, Konietschke F, Dullin C, Drebenstedt S, Hülsmann M. Comparison of hand and rotary instrumentation for removing gutta-percha from previously treated curved root canals: a microcomputed tomography study. Int Endod J. 2014;47(2):173-82. http://doi.org/10.1111/iej.12128
16. Scelza MF, Coil JM, Maciel AC, Oliveira LR, Scelza P. Comparative SEM evaluation of three solvents used in endodontic retreatment: an ex vivo study. J Appl Oral Sci. 2008;16(1):24-9. http://doi.org/10.1590/S1678-77572008000100006

17. Martos J, Gastal MT, Sommer L, Lund RG, Del Pino FA, Osinaga PW. Dissolving efficacy of organic solvents on root canal sealers. Clin Oral Investig. 2006;10(1):50-4. http://doi.org/10.1007/s00784-005-0023-2

18. Martos J, Bassotto AP, González-Rodríguez MP, Ferrer-Luque CM. Dissolving efficacy of eucalyptus and orange oil, xylol and chloroform solvents on different root canal sealers. Int Endod J. 2011;44(11):1024-8. http://doi.org/10.1111/j.1365-2591.2011.01912.x

19. Keleş A, Alcin H, Kamalak A, Versiani MA. Oval-shaped canal retreatment with self-adjusting file: a micro-computed tomography study. Clin Oral Investig. 2014;18(4):1147-53. http://doi.org/10.1007/s00784-013-1086-0

20. Erdemir A, Adanir N, Belli S. In vitro evaluation of the dissolving effect of solvents on root canal sealers. J Oral Sci. 2003;45(3):123-6. http://doi.org/10.2334/josnusd.45.123

21. Oyama KO, Siqueira EL, Santos M. In vitro study of effect of solvent on root canal retreatment. Braz Dent J. 2002;13(3):208-211. http://doi.org/10.1590/S0103-64402002000300014

22. Vajrabhaya LO, Suwannawong SK, Kamolroongwarakul R, Pewklieng L. Cytotoxicity evaluation of gutta-percha solvents: chloroform and GP-Solvent (limonene). Oral Surg Oral Med Oral Pathol Oral Radiol Endod. 2004;98(6):756-9. http://doi.org/10.1016/j.tripleo.2004.05.002

23. Kaufman D, Mor C, Stabholz A, Rotstein I. Effect of gutta-percha solvents on calcium and phosphorus levels of cut human dentin. J Endod. 1997;23(10):614-5. http://doi.org/10.1016/S0099-2399(97)80171-9

24. Topçuoğlu HS, Demirbuga S, Tuncay Ö, Arslan H, Kesim B, Yaşa B. The bond strength of endodontic sealers to root dentine exposed to different gutta-percha solvents. Int Endod J. 2014;47(12):1100-6. http://doi.org/10.1111/iej.12257

25. Rached-Júnior FJ, Souza AM, Macedo LM, Raucci-Neto W, Baratto-Filho F, Silva BM et al. Effect of root canal filling techniques on the bond strength of epoxy resin-based sealers. Braz Oral Res. 2016;30:e24. http://doi.org/10.1590/1807-3107BOR-2016.vol30.0024

26. Mjör IA, Smith MR, Ferrari M, Mannocci F. The structure of dentine in the apical region of human teeth. Int Endod J. 2001;34(5):346-53. http://doi.org/10.1046/j.1365-2591.2001.00393.x 